\title{
Estudo estratégico para o desenvolvimento do turismo sustentável nos municípios que compõem a região da AMAl no Oeste \\ Catarinense
}

O estudo aborda estratégias para o desenvolvimento sustentável do turismo nos municípios que compõem a região da Associação dos Municípios do Alto Irani AMAI de forma intermunicipal. O objetivo da pesquisa está em desenvolver um estudo estratégico que possa servir de suporte para o desenvolvimento sustentável do turismo nos municípios que compõem a região da AMAI no Oeste Catarinense. Adotamos como procedimento metodológico a pesquisa documental e a Matriz de Condicionantes, Deficiências e Potencialidades (Matriz CDP). Por meio da Matriz CDP, elaborou-se os objetivos estratégicos e as metas para o desenvolvimento sustentável do turismo. Como resultados identificamos a precária infraestrutura urbana e rural para suprir a demanda do turismo local e a falta de políticas públicas intermunicipais para o desenvolvimento sustentável do turismo. O estudo propõe um direcionamento possibilitando a correção das fragilidades e promovendo as potencialidades por meio das rotas turísticas intermunicipais como forma de criar meios que possibilitem o cumprimento dos objetivos estratégicos préestabelecidos promovendo o turismo sustentável regional.

Palavras-chave: Desenvolvimento do Turismo; Estratégias; Região da AMAI; Matriz CDP.

\section{Strategic study for the development of sustainable tourism in the municipalities that make up the AMAI region in Western Santa \\ Catarina}

\begin{abstract}
The study addresses strategies for the sustainable development of tourism in the municipalities that make up the region of the Association of Municipalities of Alto Irani - AMAI in an intermunicipal way. The objective of the research is to develop a strategic study that can support the sustainable development of tourism in the municipalities that make up the AMAI region in Western Santa Catarina. We adopted documentary research and the Matrix of Conditions, Deficiencies and Potentialities (CDP Matrix) as methodological procedure. Through the CDP Matrix, strategic objectives and goals for sustainable tourism development were elaborated. As a result, we identified the precarious urban and rural infrastructure to supply the demand for local tourism and the lack of public inter-municipal policies for the sustainable development of tourism. The study proposes a direction enabling the correction of weaknesses and promoting the potential through intercity tourist routes as a way to create means that enable the fulfillment of the pre-established strategic objectives promoting regional sustainable tourism.
\end{abstract}

Keywords: Tourism Development; Strategies; AMAI region; CDP matrix.

Topic: Planejamento, Estratégia e Competitividade

Reviewed anonymously in the process of blind peer.

Anderson Saccol Ferreira (iD

Universidade do Oeste de Santa Catarina, Brasil

http://lattes.cnpq.br/4850843904897537

http://orcid.org/0000-0002-6237-9912

anderson.ferreira@unoesc.edu.br

\section{Vanessa Matté}

Universidade do Oeste de Santa Catarina, Brasil

http://lattes.cnpq.br/1292526512030046

http://orcid.org/0000-0002-1524-4433.

vaane.matte@hotmail.com
Received: 09/10/2020

Approved: 22/12/2020
Referencing this:

FERREIRA, A. S.; MATTÉ, V.. Estudo estratégico para o desenvolvimento do turismo sustentável nos municípios que compõem a região da AMAI no Oeste Catarinense. Revista Brasileira de Administração Científica, v.11, n.4, p.118-131, 2020. DOI: http://doi.org/10.6008/CBPC2179-684X.2020.004.0009 


\section{INTRODUÇÃO}

$\mathrm{Na}$ atualidade o Brasil representa a $9^{\circ}$ economia turística do mundo conforme aponta World Travel e Tourism Council - WTTC ${ }^{1}$. Todo os anos o turismo movimenta diretamente e indiretamente cerca de $\mathrm{R} \$ 492$ bilhões, correspondente a $9,6 \%$ do Produto Interno Bruto (PIB), com 52 ramos de atividades como hospedagem, alimentação, agências de viagens e setor aéreo, os quais, geram mais de 3 milhões de postos de trabalho com empresas de toda a parte do território nacional (ICTN, 2015).

Diante dessas oportunidades, há necessidade preparar os municípios criando estratégias para melhorar o posicionamento no mercado onde atuam ou pretendem atuar sempre de forma sustentável, ou seja, sem comprometer as futuras gerações. Nesse contexto, o tema da pesquisa aborda as estratégias do turismo nos municípios que compõem a região da Associação dos Municípios do Alto Irani (AMAI) no oeste de Santa Catarina. A pergunta de pesquisa surge com a seguinte indagação: como fortalecer o desenvolvimento do turismo na região da Associação dos Municípios do Alto Irani no Oeste Catarinense?

O objetivo está delimitado em desenvolver um estudo estratégico que possa servir de suporte para o desenvolvimento sustentável do turismo nos municípios que compõem a região da AMAl em Santa Catarina. Adotamos como procedimentos metodológicos a pesquisa documental, por meio das Leis orgânicas municipais, Plano Diretores, indicadores de desenvolvimento humano e sustentável. Utilizamos a Matriz de Condicionantes, Deficiências e Potencialidades (Matriz CDP) para identificar e visualizar dos principais pontos críticos e suas potencialidades de forma a facilitar a elaboração dos objetivos estratégicos e metas para o desenvolvimento sustentável do turismo. $O$ universo da pesquisa investiga é composta pelos municípios de Abelardo Luz, Bom Jesus, Entre Rios, Faxinal dos Guedes, Ipuaçu, Lajeado Grande, Marema, Ouro Verde, Ponte Serrada, Passos Maia, São Domingos, Vargeão, Xanxerê e Xaxim, que juntos compõe a região da AMAI.

Os resultados encontrados na Matriz CDP demostram as principais deficiências na infraestrutura dos municípios, bem como a falta de políticas públicas que instiguem a promoção do turismo sustentável, impactando diretamente na demanda e oferta turística, no processo de venda, e nos atrativos turísticos. A pesquisa propõe um direcionamento possibilitando a correção das fragilidades e promovendo as potencialidades por meio das rotas turísticas intermunicipais como forma de criar meios que possibilitem o cumprimento dos objetivos estratégicos pré-estabelecidos promovendo o turismo sustentável regional.

Além dessa introdução o artigo esta estrutura em seis etapas sendo o turismo na região da AMAI, procedimento metodológico, os resultados obtidos pela Matriz de Condicionantes, Deficiências e Potencialidades (CDP), e finalizando a pesquisa as considerações finais.

\section{REVISÃO TEÓRICA}

\section{O turismo na região da Associação dos Municípios do Alto Irani}

A Associação dos Municípios do Alto Irani (AMAI), foi criada pelo Decreto Estadual 5855/78 (BRASIL, 1978), estando localizada no Oeste do Estado de Santa Catarina. Na atualidade a associação tem a finalidade

\footnotetext{
${ }^{1}$ https://wttc.org/Research/Economic-Impact
} 
de auxiliar o desenvolvimento dos municípios associados com esfera autônoma de governo, ou seja, fortalecendo a capacidade dos municípios na formulação de políticas públicas de forma a fomentar o desenvolvimento regional (AMAI, 2017).

Seu território abrange 14 municípios, Abelardo Luz, Bom Jesus, Entre Rios, Faxinal dos Guedes, Ipuaçu, Lajeado Grande, Marema, Ouro Verde, Ponte Serrada, Passos Maia, São Domingos, Vargeão, Xanxerê e Xaxim. É por meio das associações que muitas atividades intermunicipais são desenvolvidas, ou seja, ela reúne diversos municípios visando a realização de ações conjuntas produzidas pelos municípios de forma a facilitar resultados bem-sucedidos nos aspectos, sociocultural, ambiental, político institucional e econômico.

Na região Oeste o turismo tem sido um forte fator de desenvolvimento, pois serve como motivador para o desenvolvimento de vários setores da economia. Molina (2003) aponta que o turismo na região Oeste sempre esteve relacionado ao comercio, visitação em agroindústrias e pela fé. Passando a ser relacionado com a qualidade de vida, quando proporciona o abandono da rotina a mudança de local e clima regenerando a resistência física e psicológica do indivíduo (WAHAB, 1991). A qualidade de vida tem sido um dos principais fatores pela busca do turismo o que passa a resultar constantes investimentos em infraestrutura no estado. Os investimentos públicos e privados ocorridos em 2015 resultaram em um crescimento de mais de 1,1 milhões de turistas no estado Catarinense tendo $20 \%$ de aumento em 2016 (SANTA CATARINA, 2016).

Esse crescimento reflete na geração de emprego e renda e no desenvolvimento de novas atividades econômicas. Em consequências adversas temos a super utilização da infraestrutura urbana, que em períodos de alta temporada passam a gerar custos de manutenção. Bezerra (2003) descreve outro viés sendo indispensável a implementação de políticas públicas voltadas a qualificar e ampliar o turismo, principalmente ao desenvolvimento sustentável local. Para FIESC (2016), há dificuldades para planejar e executar as políticas públicas de forma que possa fortalecer o turismo como atividade economicamente sustentável. Ainda a deficiência na infraestrutura e carência em informações sistematizadas e em conhecimento para tomada de decisões, bem como, deficiências na qualificação profissional e metodologias para elaborar a oferta de produtos turísticos (FIESC, 2016).

Estes obstáculos passam a enfraquecer o turismo local, principalmente nos municípios de estudo, que por terem suas principais atividades econômicas voltadas a agroindústrias muitas vezes não se preocupam a desenvolver as políticas públicas acerca do turismo ou a inclui-las dentro do Plano Diretor municipal, aliás ponto fundamental para gerir o turismo sustentável.

No sentido de elencar os pontos fortes e os obstáculos Boullón (2002) enfatiza que os agentes devem ser analisados por partes que o caracterizam como: a demanda turística, a oferta turística, o processo de venda, o produto turístico, o empreendimento e os atrativos turísticos, a infraestrutura, a superestrutura e a síntese do sistema turístico. Estes pontos levantados devem compreender como parte do planejamento estratégico, visando o pleno funcionamento de todo um sistema turístico, ou seja, este sistema apresentase de forma como um processo racional de decisões, sistematizadas que remetam o pensamento no presente, passado e futuro (RUSCHMANN, 1997).

Para Beni (1999), o planejamento estratégico do turismo trata de um sistema inter-relacionado, pois 
a necessidade da oferta e demanda. Para o autor a oferta compreende os atrativos turísticos e seus equipamentos de infraestrutura já a "demanda são os mercados de turismo internacional e doméstico que utilizam atrativos, equipamentos e serviços turísticos” (BENI, 1999). Desta forma, os atrativos turísticos podem ser considerados as características locais ou até mesmo as atividades desenvolvidas em função delas.

Estes atrativos em conjunto com a oferta do turismo podem ser caracterizados como produto turístico, ou seja, este processo de planejamento deverá apresentar a determinação do objetivo, o inventário de todos os recursos turísticos naturais, culturais, diferenciais, análise em síntese da situação encontrada, formulação da política e do plano de turismo, e recomendações de viabilidade (BENI, 1999).

Todo o planejamento deverá ser integrado onde os objetivos estratégicos cumpram as metas de curto, médio e longo prazo. Os planos a longo prazo passam a referir aos objetivos específicos que devem estar vinculados a um futuro determinado. Nesse sentido as ações descritas a serem realizadas no momento atual respeitando as metas, considerando as necessidades e consequências futuras, ou seja, só podemos incorporar as ações pensando e planejando na medida em que formos conhecendo o passado (BRASIL, 2007). Já o planejamento estratégico deve estar direcionado a identificar e solucionar questões imediatas a curto e médio prazo estando estes voltados a mudar rapidamente situações necessárias (BENI, 1999).

Todavia, de nada irá adiantar planejar os municípios por meio planejamento estratégico sustentável do turismo se não refletir no apoio e participação efetiva da população. É através dela que o poder público municipal irá cumprir as metas e promover as políticas públicas voltadas ao turismo sustentável, garantindo e satisfazendo as necessidades dos turistas e as necessidades socioeconômicas da região em estudo.

\section{METODOLOGIA}

Aborda nos procedimentos metodológicos os aspectos que visam alcançar os objetivos da pesquisa. O cenário da pesquisa demonstrado no Figura 1 apresenta a localização geográfica dos 14 municípios do estudo.

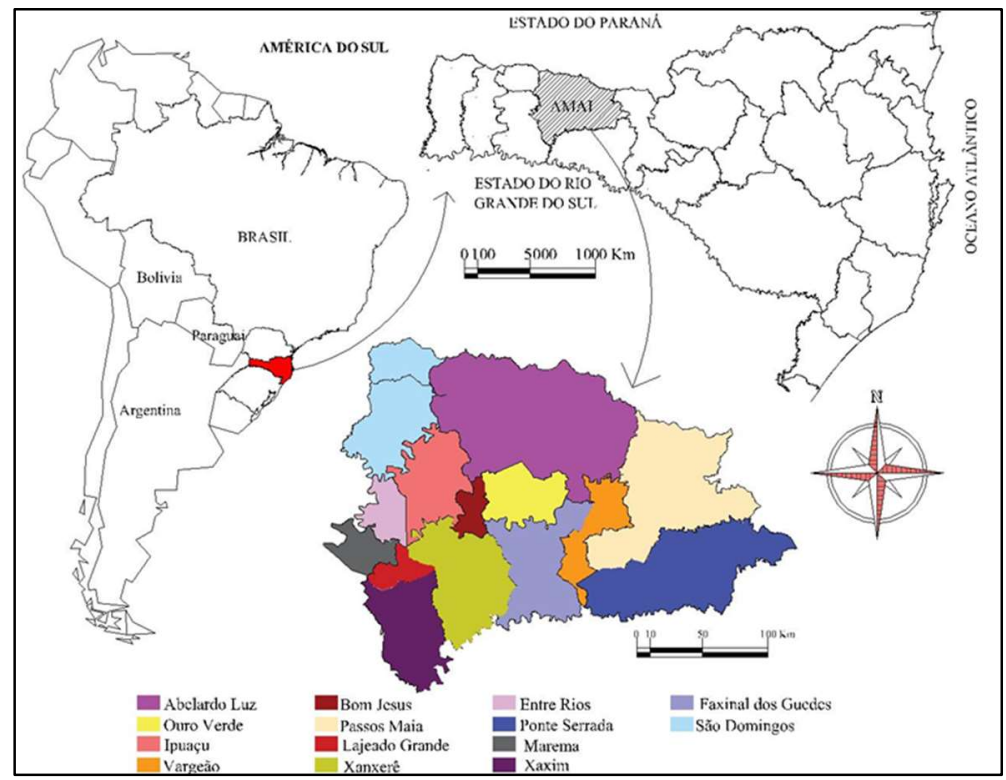

Figura 1: Localização geográfica. Fonte: adaptado de IBGE (2013). 
O artigo traz uma abordagem qualitativa que permite diagnosticar quais são os pontos fracos e os pontos fortes de cada município. Permite criar estratégias para fomentar o turismo de forma sustentável integrando todos os municípios da região. Adotamos como procedimento metodológico a pesquisa documental que permitiu investigar documentos que ainda não sofreram nenhum tratamento analítico (HELDER, 2006). Estes documentos utilizados podem ser citados como os Planos Diretores, relatórios oficiais cedidos pelas prefeituras municipais e os indicadores de desenvolvimento municipal sustentável. Estes servem como base para entender o produtor turístico e a infraestrutura disponível para atender a demanda do turismo na região.

Buscamos com a Matriz de Condicionantes, Deficiências e Potencialidades (CDP) identificar quais são as principais características turísticas existentes, de forma a mesurar os pontos fracos e fortes propondo alternativas sustentáveis acerca do turismo na região. A utilização da Matriz consiste na classificação de elementos que possam definir a estrutura do turismo, onde o pesquisado por meio de conhecimento técnico e científico atribuirá a cada um dos elementos uma função dentro do processo de desenvolvimento. É importante ressaltar que a elaboração da Matriz CDP foi realizada in loco em todos os municípios citados na pesquisa. Buscamos validar e complementar a pesquisa documental aumentando qualidade e a aplicabilidade dos dados coletados.

O método CDP é empregado em projetos de planejamento e desenvolvimento urbano e regional. "Trata-se de uma sistemática de organização de dados levantados que possibilita sua visão em conjunto e apresentação de forma compreensível e de fácil visualização, sendo por este motivo um instrumento muito útil na apresentação e discussão do Plano Diretor [...]" (SIEBERT et al., 1998). O método representa uma operacionalização sistemática dos problemas, buscando por meio do levantamento de dados uma apresentação compreensível, facilmente visualizada e de fácil entendimento com a situação da área estudada. Por esta característica, o método é muito utilizado na formulação de diagnóstico de Planos Diretores e sua representação é em forma de Matriz (SANTA CATARINA, 1999).

Os resultados obtidos na realização desta pesquisa podem dar suporte para tomada de decisões dos gestores. Eles visam auxiliar no desenvolvimento de estratégias para elevar os indicadores de desenvolvimento municipal sustentável promovendo o turismo sustentável na ótica intermunicipal, corrigindo as fragilidades e elevando as potencialidades como qualidade de vida e a geração econômica das atividades turísticas dos municípios que compões a região da AMAI.

\section{RESULTADOS E DISCUSSÃO}

\section{Resultados da matriz de Condicionantes, Deficiências e Potencialidades (CDP)}

As associações microrregionais são entidades formadas por grupos de municípios, com interesse e características territoriais comuns, que unificadas buscam o fortalecimento da região. $\mathrm{O}$ Estado Catarinense contempla na atualidade 21 associações compostas por agrupamentos de municípios. Entretanto, associação da AMAI, configura uma unificação de 14 municípios que segundo o IBGE (2014), são considerados de porte 
pequeno, por possuir população inferior a 100 mil habitantes. Além disso, ambas as cidades possuem semelhanças, pois suas principais atividades econômicas estão voltadas para agroindústrias, suinocultura, avicultura e agricultura. A Tabela 1 demonstra as características dos municípios que compõem a região da AMAI.

Tabela 1: Características dos municípios da região da AMAl.

\begin{tabular}{|c|c|c|c|c|c|}
\hline Município & $\begin{array}{l}\text { População } \\
\text { estimada } 2016\end{array}$ & $\begin{array}{l}\text { IDHM } \\
2010\end{array}$ & $\begin{array}{l}\text { IDMS } \\
2016\end{array}$ & $\begin{array}{l}\text { Densidade demográfica } \\
\text { 2010(hab./(km²) }\end{array}$ & Principal atividade econômica \\
\hline Abelardo Luz & 17782 & 0,696 & 0,532 & 17,94 & $\begin{array}{l}\text { Agroindústria } \\
\text { Turismo }\end{array}$ \\
\hline Bom Jesus & 2870 & 0,718 & 0,538 & 39,80 & Agropecuária \\
\hline Entre rios & 3167 & 0,657 & 0,503 & 28,87 & Agricultura e Suinocultura \\
\hline $\begin{array}{l}\text { Faxinal dos } \\
\text { Guedes }\end{array}$ & 10758 & 0,758 & 0,655 & 31,38 & $\begin{array}{l}\text { Indústria de Papel } \\
\text { Agropecuária }\end{array}$ \\
\hline Ipuaçu & 7331 & 0,66 & 0,467 & 26,06 & Extração de Madeira \\
\hline $\begin{array}{l}\text { Lajeado } \\
\text { Grande }\end{array}$ & 1461 & 0,771 & 0,525 & 22,82 & Agricultura \\
\hline Marema & 1952 & 0,743 & 0,534 & 21,17 & Agropecuária e Agricultura \\
\hline Ouro Verde & 2254 & 0,695 & 0,527 & 12,00 & Agricultura \\
\hline Passos Maia & 4279 & 0,659 & 0,579 & 7,15 & Extração de Madeira \\
\hline Ponte Serrada & 11031 & 0,693 & 0,580 & 19,54 & Agricultura \\
\hline São Domingo & 9509 & 0,765 & 0,565 & 24,68 & Suinocultura e Avicultura \\
\hline Vargeão & 3590 & 0,686 & 0,599 & 21,19 & $\begin{array}{l}\text { Agricultura, pecuária, comércio } \\
\text { e indústria }\end{array}$ \\
\hline Xanxerê & 49057 & 0,774 & 0,661 & 116,81 & Suinocultura e agricultura \\
\hline Xaxim & 27921 & 0,752 & 0,642 & 87,67 & Agropecuária e Agroindústria \\
\hline
\end{tabular}

Fonte: De IBGE (2016)

Percebe-se que $50 \%$ dos municípios possuem o indicador de desenvolvimento humano superior a 0,7 , e nenhum deles possui indicador de desenvolvimento municipal sustentável superior a 0,7. Este indicador torna-se preocupante quando se pretende implantar metas para o desenvolvimento sustentável municipal.

Quando comparamos os indicadores de desenvolvimento sustentável na esfera sociocultural percebemos uma ascensão de 2012 para 2016, diferente da esfera ambiental e político institucional de demonstra um decréscimo nos indicadores conforme demonstrado na Figura 2.

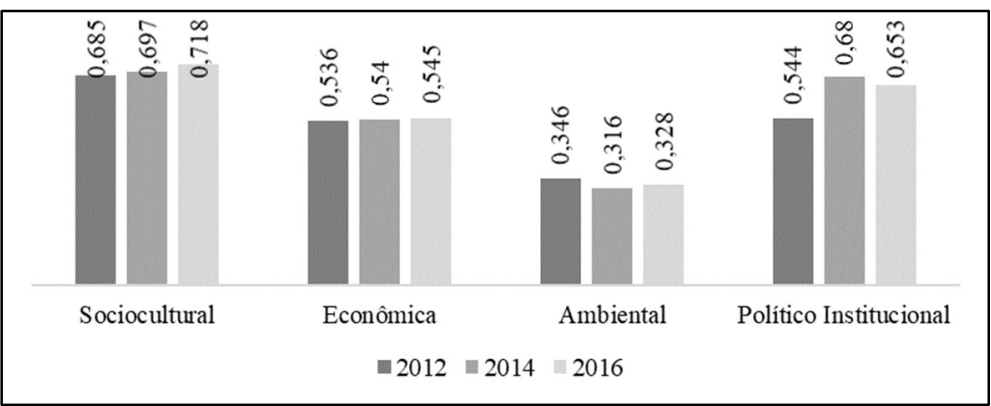

Figura 2: Gráfico de indicadores de desenvolvimento sustentável da AMAI. Fonte: de FECAM (2016)

Estes indicadores causam grande impacto no turismo pois refletem a realidade em que os municípios se encontram, principalmente quando tratamos de questões sustentáveis. Conforme aponta Sachs (2008), a sustentabilidade só será alcançada se todas as suas dimensões estiverem em equilíbrio, ou seja, a esfera social, cultura e econômica encontram equilibradas com uma acessão. Já a esfera ambiental e político institucional demostram um decréscimo que pode ocasionar grandes problemas na estruturação estratégica 
para o desenvolvimento do turismo na região da AMAl. Estas características são claramente demostradas na Matriz CDP.

É nesse ponto que levantamos os pontos fortes e fracos, internos e externos de forma a identificar as fragilidades e as potencialidades propondo formas de promover o turismo sustentável nos municípios que compõem a região da AMAI. Na Matriz de Condicionantes, Deficiências e Potencialidades (CDP), demostrada no Quadro1 é possível identificar três esferas consideradas fundamentais para o desenvolvimento do turismo, ou seja, a esfera territorial, ambiental e político institucional de cada município.

Quadro 1: Matriz (CDP), esfera territorial, ambiental e político institucional.

\begin{tabular}{|c|c|c|c|}
\hline Município & Condicionantes & Deficiências & Potencialidades \\
\hline Abelardo Luz & $\begin{array}{l}\text { Município limítrofes, São } \\
\text { Domingos, Ipuaçu, Bom } \\
\text { Jesus, Ouro Verde, Faxinal } \\
\text { dos Guedes, Vargeão e } \\
\text { Passos Maia; } \\
\text { Relevo com pouco declive; } \\
\text { Rio Chapecó corta o } \\
\text { município; }\end{array}$ & $\begin{array}{l}\text { Indicador muito baixo dos } \\
\text { domicílios com acesso à rede } \\
\text { geral de esgoto ou fossa } \\
\text { séptica; não possui Agenda } \\
21 \text { local; indicador muito } \\
\text { baixo de licenciamento de } \\
\text { impacto local; poucos } \\
\text { mobiliários urbanos em } \\
\text { pontos turísticos; poucos } \\
\text { bancos e lixeiras; falta de } \\
\text { informação nos } \\
\text { equipamentos turísticos e } \\
\text { vias municipais; pouca } \\
\text { participação em consórcios } \\
\text { públicos intermunicipais; } \\
\text { baixa participação nos pleitos } \\
\text { eleitorais com } 34 \%\end{array}$ & $\begin{array}{l}\text { Praça central ampliada e com } \\
\text { estrutura para eventos; } \\
\text { calçadas largas; bom } \\
\text { indicador de áreas de matas e } \\
\text { florestas naturais } \\
\text { preservadas nas } \\
\text { propriedades } \\
\text { agropecuárias; Possibilidades } \\
\text { de exploração do turismo } \\
\text { ambiental; beleza cênica; } \\
\text { grande potencial de } \\
\text { exploração do turismo nas } \\
\text { quedas do rio Chapecó; } \\
\text { quantidade de biodiversidade } \\
\text { dos atrativos naturais. }\end{array}$ \\
\hline Bom Jesus & $\begin{array}{l}\text { O relevo é considerado de } \\
\text { médio ondulado; municípios } \\
\text { limítrofes: Ipuaçu, Abelardo } \\
\text { Luz, Ouro Verde, Faxinal dos } \\
\text { Guedes e Xanxerê. }\end{array}$ & $\begin{array}{l}26 \% \text { dos domicílios com } \\
\text { acesso à rede geral de esgoto } \\
\text { ou fossa séptica; baixo } \\
\text { indicador referente a Agenda } \\
21 \text { local e licenciamento de } \\
\text { impacto local; } 35 \% \text { áreas de } \\
\text { matas e florestas naturais } \\
\text { preservadas nas } \\
\text { propriedades agropecuárias; } \\
\text { o município não possui } \\
\text { pontos turísticos relevantes; } \\
\text { poucos bancos e lixeiras; } 45 \% \\
\text { de participação nos pleitos } \\
\text { eleitorais }\end{array}$ & $\begin{array}{l}\text { Há participação em } \\
\text { consórcios públicos } \\
\text { intermunicipais; ruas bem } \\
\text { sinalizadas; permite } \\
\text { implantação de rota turística; } \\
\text { localização geográfica facilita } \\
\text { a ligação entre os municípios } \\
\text { vizinhos; inclusão das áreas } \\
\text { rurais em ações voltadas ao } \\
\text { turismo; o município preza o } \\
\text { respeito ao meio ambiente e } \\
\text { sua exploração } \\
\text { ecologicamente correta. }\end{array}$ \\
\hline Entre Rios & $\begin{array}{l}\text { Relevo de planaltos fortes e } \\
\text { ondulados; Município está } \\
\text { entre dois rios, Presença de } \\
\text { usina hidrelétrica municípios } \\
\text { limítrofes: São Domingos, } \\
\text { Ipuaçu, Marema, Quilombo, } \\
\text { Lajeado Grande e Xanxerê. }\end{array}$ & $\begin{array}{l}\text { Calçadas em condições } \\
\text { precárias e sem } \\
\text { acessibilidade; pouca } \\
\text { diversidade de atrativos } \\
\text { estruturados para receber os } \\
\text { turistas; baixo indicador de } \\
\text { domicílios atendidos direta } \\
\text { ou indiretamente por coleta } \\
\text { de lixo, domicílios atendidos } \\
\text { por rede pública de água, } \\
\text { domicílios com acesso à rede } \\
\text { geral de esgoto ou fossa } \\
\text { séptica, baixo indicado da } \\
\text { Agenda } 21 \text { local e } \\
\text { licenciamento de impacto } \\
\text { local; } 35 \% \text { áreas de matas e } \\
\text { florestas naturais } \\
\text { preservadas nas } \\
\text { propriedades agropecuárias. }\end{array}$ & $\begin{array}{l}\text { Praça central ampla podendo } \\
\text { ser utilizada para eventos; } \\
\text { reserva indígena Kaingang e } \\
\text { Guarani; } 67 \% \\
\text { representatividade de } \\
\text { gêneros entre candidatos a } \\
\text { vereadores; preservação da } \\
\text { cultura indígena; existência } \\
\text { de grupos culturais. } \\
\text { (Indígena); Existência de } \\
\text { pedras preciosas com } \\
\text { extração consciente; possui } \\
\text { rotas e trilhas em meio a } \\
\text { mata nativa; exploração da } \\
\text { atividade turística por meio } \\
\text { da extração das pedras } \\
\text { preciosas. }\end{array}$ \\
\hline
\end{tabular}




\begin{tabular}{|c|c|c|c|}
\hline Faxinal dos Guedes & $\begin{array}{l}\text { Relevo com declive } \\
\text { moderado; formação } \\
\text { constante de nevoeiros, } \\
\text { município limítrofes: } \\
\text { Xanxerê, Xavantina, } \\
\text { Ipumirim, Vargeão, Abelardo } \\
\text { Luz, Ouro Verde e Bom Jesus. }\end{array}$ & $\begin{array}{l}\text { Algumas calçadas irregulares } \\
\text { e sem acessibilidade; BR282 } \\
\text { corta a cidade sem elevados } \\
\text { para facilitar a circulação dos } \\
\text { munícipes; falta de existência } \\
\text { de conselho municipal de } \\
\text { cultura em atividade; } 49 \% \\
\text { dos domicílios com acesso à } \\
\text { rede geral de esgoto ou fossa } \\
\text { séptica; baixo indicado da } \\
\text { Agenda } 21 \text { local e } \\
\text { licenciamento de impacto } \\
\text { local; } 56 \% \text { dos domicílios } \\
\text { atendidos por rede pública de } \\
\text { água; } 47 \% \text { participação nos } \\
\text { pleitos eleitorais; pouca } \\
\text { participação em consórcios } \\
\text { públicos intermunicipais; }\end{array}$ & $\begin{array}{l}\text { Construção de um centro de } \\
\text { eventos; ruas organizadas, } \\
\text { limpas e bem sinalizadas; } \\
\text { pontos de revenda de } \\
\text { materiais artesanais; } 100 \% \text { de } \\
\text { áreas de matas e florestas } \\
\text { naturais preservadas nas } \\
\text { propriedades agropecuárias; } \\
\text { potencial turístico em áreas } \\
\text { rurais pincipalmente para } \\
\text { explorar rotas turísticas } \\
\text { naturais; }\end{array}$ \\
\hline Ipuaçu & $\begin{array}{l}\text { Reserva indígena; município } \\
\text { limítrofes: Entre Rios, São } \\
\text { Domingos, Abelardo Luz, } \\
\text { Bom Jesus e Xanxerê. }\end{array}$ & $\begin{array}{l}\text { Lixeira e calçadas em estado } \\
\text { precário sem acessibilidade; } \\
\text { deficiência na inclusão de } \\
\text { áreas rurais em ações } \\
\text { voltadas ao turismo } \\
\text { municipal; falta de existência } \\
\text { de conselho municipal de } \\
\text { cultura em atividade; baixo } \\
\text { indicador de domicílios } \\
\text { atendidos direta ou } \\
\text { indiretamente por coleta de } \\
\text { lixo, domicílios atendidos por } \\
\text { rede pública de água, } \\
\text { domicílios com acesso à rede } \\
\text { geral de esgoto ou fossa } \\
\text { séptica, sem implantação da } \\
\text { Agenda } 21 \text { local e } \\
\text { licenciamento de impacto } \\
\text { local; } 47 \% \text { das áreas de matas } \\
\text { e florestas naturais } \\
\text { preservadas nas } \\
\text { propriedades agropecuárias. }\end{array}$ & $\begin{array}{l}\text { Perímetro urbano pequeno e } \\
\text { com quadras } \\
\text { regulares; reserva indígena } \\
\text { Xapecó; possível exploração } \\
\text { da área indígena para o } \\
\text { turismo; possibilidade de } \\
\text { exploração do turismo rural; } \\
\text { preservação da cultura } \\
\text { indígena; existência de } \\
\text { grupos culturais. (Indígena); } \\
\text { potencial turístico em áreas } \\
\text { rurais; quantidade de } \\
\text { biodiversidade dos atrativos } \\
\text { naturais. }\end{array}$ \\
\hline Lajeado Grande & $\begin{array}{l}\text { O relevo fortemente } \\
\text { ondulado; Clima } \\
\text { mesotérmico úmido; } \\
\text { municípios Limítrofes: } \\
\text { Marema, Entre Rios e } \\
\text { Xanxerê, Xaxim }\end{array}$ & $\begin{array}{l}\text { Calçadas sem acessibilidade; } \\
\text { Falta de existência de } \\
\text { conselho municipal de } \\
\text { cultura em atividade; } \\
\text { ausência de rotas que } \\
\text { explorem o turismo do } \\
\text { município; } 21 \% \text { dos } \\
\text { domicílios atendidos direta } \\
\text { ou indiretamente por coleta } \\
\text { de lixo; } 8 \% \text { dos domicílios } \\
\text { atendidos por rede pública de } \\
\text { água; baixo indicador de } \\
\text { domicílios com acesso à rede } \\
\text { geral de esgoto ou fossa } \\
\text { séptica; } 30 \% \text { de áreas de } \\
\text { matas e florestas naturais } \\
\text { preservadas nas } \\
\text { propriedades agropecuárias; } \\
\text { sem implantação da Agenda } \\
21 \text { local e licenciamento de } \\
\text { impacto local. }\end{array}$ & $\begin{array}{l}\text { Calçadas largas e com recuo } \\
\text { adequado; infraestrutura do } \\
\text { município permite } \\
\text { implantação de rotas } \\
\text { turísticas; possibilidade de } \\
\text { incentivos em atividades } \\
\text { culturais; quantidade de } \\
\text { biodiversidade dos atrativos } \\
\text { naturais; possibilidade de } \\
\text { criação de rota turística; }\end{array}$ \\
\hline Marema & $\begin{array}{l}\text { Clima mesotérmico úmido; } \\
\text { municípios limítrofes: Xaxim, } \\
\text { Lajeado Grande, Quilombo, } \\
\text { Coronel Freitas, Cordilheira } \\
\text { Alta, Xanxerê. }\end{array}$ & $\begin{array}{l}\text { Falta de revendas de } \\
\text { artesanatos; } 25 \% \text { domicílios } \\
\text { atendidos direta ou } \\
\text { indiretamente por coleta de } \\
\text { lixo; } 4 \% \text { de domicílios } \\
\text { atendidos por rede pública de }\end{array}$ & $\begin{array}{l}\text { Cultura italiana } \\
\text { predominante no munício; } \\
\text { cultivação da cultura, } \\
\text { repassando o conhecimento } \\
\text { artesanal de geração em } \\
\text { geração; Início da exploração }\end{array}$ \\
\hline
\end{tabular}




\begin{tabular}{|c|c|c|c|}
\hline & & $\begin{array}{l}\text { água; baixo indicador de } \\
\text { domicílios com acesso à rede } \\
\text { geral de esgoto ou fossa } \\
\text { séptica; } 25 \% \text { de áreas de } \\
\text { matas e florestas naturais } \\
\text { preservadas nas } \\
\text { propriedades agropecuárias; } \\
\text { sem implantação da Agenda } \\
21 \text { local e licenciamento de } \\
\text { impacto local. }\end{array}$ & $\begin{array}{l}\text { de pedras preciosas; } \\
\text { quantidade de biodiversidade } \\
\text { dos atrativos naturais; } \\
\text { potencial para rotas turísticas } \\
\text { em áreas rurais. }\end{array}$ \\
\hline Ouro Verde & $\begin{array}{l}\text { O município tem acesso pela } \\
\text { BR 155; municípios limítrofes: } \\
\text { Abelardo Luz, Faxinal dos } \\
\text { Guedes, Bom Jesus. }\end{array}$ & $\begin{array}{l}\text { Existência de lixeiras, porém } \\
\text { não o suficiente com } \\
\text { acumulo de resíduos em } \\
\text { alguns pontos centrais do } \\
\text { município; Falta de existência } \\
\text { de conselho municipal de } \\
\text { cultura em atividade; poucos } \\
\text { investimentos em cultura e } \\
\text { em atividades de lazer; } 33 \% \\
\text { de domicílios atendidos } \\
\text { direta ou indiretamente por } \\
\text { coleta de lixo; } 6 \% \text { de } \\
\text { domicílios atendidos por rede } \\
\text { pública de água; baixo } \\
\text { indicador de domicílios com } \\
\text { acesso à rede geral de esgoto } \\
\text { ou fossa séptica; } 19 \% \text { de } \\
\text { áreas de matas e florestas } \\
\text { naturais preservadas nas } \\
\text { propriedades agropecuárias }\end{array}$ & $\begin{array}{l}\text { Perímetro urbano pequeno e } \\
\text { organizado; diversidade de } \\
\text { eventos; quantidade de } \\
\text { biodiversidade dos atrativos } \\
\text { naturais; bom indicador de } \\
\text { fianças públicas, gestão } \\
\text { pública e participação social; } \\
63 \% \text { de representatividade de } \\
\text { gêneros entre candidatos a } \\
\text { vereadores; possibilidade de } \\
\text { implantação de rotas } \\
\text { turísticas rurais; }\end{array}$ \\
\hline Passos Mais & $\begin{array}{l}\text { Municípios limítrofes: Água } \\
\text { Doce, Faxinal dos Guedes, } \\
\text { Ponte Serrada, Vargeão e } \\
\text { Irani; Rio Chapecó corta o } \\
\text { município; }\end{array}$ & $\begin{array}{l}\text { Ruas estreitas e } \\
\text { desorganizadas; } 14 \% \text { de } \\
\text { domicílios atendidos direta } \\
\text { ou indiretamente por coleta } \\
\text { de lixo; } 02 \% \text { de domicílios } \\
\text { atendidos por rede pública de } \\
\text { água; } 12 \% \text { de domicílios com } \\
\text { acesso à rede geral de esgoto } \\
\text { ou fossa séptica; } 30 \% \text { de } \\
\text { participação nos pleitos } \\
\text { eleitorais; sem implantação } \\
\text { da Agenda } 21 \text { local e } \\
\text { licenciamento de impacto } \\
\text { local. }\end{array}$ & $\begin{array}{l}\text { Praça municipal ampla e com } \\
\text { boa estrutura; quadra } \\
\text { esportiva de areia para o } \\
\text { lazer dos munícipes; } \\
\text { apresenta alto indicador de } \\
\text { áreas de matas e florestas } \\
\text { naturais preservadas nas } \\
\text { propriedades agropecuárias e } \\
\text { participação em consórcios } \\
\text { públicos intermunicipais; } \\
\text { potencial turístico em áreas } \\
\text { rurais; quantidade de } \\
\text { biodiversidade dos atrativos } \\
\text { naturais. }\end{array}$ \\
\hline Ponte Serrada & $\begin{array}{l}\text { O relevo fortemente } \\
\text { ondulado; municípios } \\
\text { limítrofes: Passos Maia, Água } \\
\text { Doce, Lindóia do Sul, Irani, } \\
\text { Vargem Bonita, Ipumirim e } \\
\text { Vargeão. }\end{array}$ & $\begin{array}{l}\text { Poucos bancos e lixeiras; rio } \\
\text { corta o perímetro urbano em } \\
\text { degradação e com } \\
\text { edificações muito próximas } \\
\text { das suas margens; falta de } \\
\text { existência de conselho } \\
\text { municipal de cultura em } \\
\text { atividade; } 56 \% \text { de domicílios } \\
\text { atendidos por rede pública de } \\
\text { água; baixo indicador de } \\
\text { domicílios com acesso à rede } \\
\text { geral de esgoto ou fossa } \\
\text { séptica; pouca participação } \\
\text { da Agenda } 21 ;\end{array}$ & $\begin{array}{l}\text { Infraestrutura do município } \\
\text { permite implantação de rotas } \\
\text { turísticas; diversidade de } \\
\text { eventos; estrutura em } \\
\text { homenagem a nossa senhora } \\
\text { aparecida e palco do evento; } \\
\text { potencial turístico em áreas } \\
\text { rurais; belezas naturais e } \\
\text { biodiversidade; } 81 \% \text { dos } \\
\text { domicílios atendidos direta } \\
\text { ou indiretamente por coleta } \\
\text { de lixo; } 100 \% \text { de áreas de } \\
\text { matas e florestas naturais } \\
\text { preservadas nas } \\
\text { propriedades agropecuárias. }\end{array}$ \\
\hline São Domingos & $\begin{array}{l}\text { Município com acesso pela } \\
\text { BR 480, BR } 156 \text { e BR 482; } \\
\text { Município limítrofes: Galvão, } \\
\text { Coronel Martins, Santiago do } \\
\text { Sul, Quilombo, Entre Rios, } \\
\text { Ipuaçu e Abelardo Luz. }\end{array}$ & $\begin{array}{l}\text { Pouca diversidade de } \\
\text { atrativos estruturados para } \\
\text { receber os turistas; falta de } \\
\text { existência de conselho } \\
\text { municipal de cultura em } \\
\text { atividade; } 45 \% \text { dos domicílios } \\
\text { atendidos direta ou } \\
\text { indiretamente por coleta de }\end{array}$ & $\begin{array}{l}\text { Eventos anuais com recepção } \\
\text { de grandes públicos; ruas e } \\
\text { calçadas largas com bom } \\
\text { recuo das edificações; } \\
\text { diversidade de eventos; feira } \\
\text { anual com recepção de } \\
\text { grande público e diversidade } \\
\text { de shows; quantidade de }\end{array}$ \\
\hline
\end{tabular}




\begin{tabular}{|c|c|c|c|}
\hline & & $\begin{array}{l}\text { lixo; } 45 \% \text { de domicílios } \\
\text { atendidos por rede pública de } \\
\text { água; baixo indicador de } \\
\text { domicílios com acesso à rede } \\
\text { geral de esgoto ou fossa } \\
\text { séptica; } 59 \% \text { de áreas de } \\
\text { matas e florestas naturais } \\
\text { preservadas nas } \\
\text { propriedades agropecuárias; } \\
\text { pouca participação da } \\
\text { Agenda } 21 e \text { licenciamento de } \\
\text { impacto local. }\end{array}$ & $\begin{array}{l}\text { biodiversidade dos atrativos } \\
\text { naturais; conta com um } \\
\text { parque estadual araucárias. }\end{array}$ \\
\hline Vargeão & $\begin{array}{l}\text { Relevo acentuado; município } \\
\text { limítrofes: Faxinal dos } \\
\text { Guedes, Ponte Serrada, } \\
\text { Passos Maia e Abelardo Luz. }\end{array}$ & $\begin{array}{l}24 \% \text { de domicílios atendidos } \\
\text { por rede pública de água; } \\
13 \% \text { de domicílios com } \\
\text { acesso à rede geral de esgoto } \\
\text { ou fossa séptica; } 60 \% \text { de } \\
\text { domicílios atendidos direta } \\
\text { ou indiretamente por coleta } \\
\text { de lixo; pouca participação da } \\
\text { Agenda } 21 e \text { licenciamento de } \\
\text { impacto local. }\end{array}$ & $\begin{array}{l}\text { Perímetro urbano pequeno e } \\
\text { muito bem organizado; } \\
\text { calçadas em ótimo estado e } \\
\text { acessibilidade na maioria } \\
\text { delas; praça ampla para } \\
\text { eventos; potencial turístico } \\
\text { em áreas rurais; quantidade } \\
\text { de biodiversidade dos } \\
\text { atrativos naturais; }\end{array}$ \\
\hline Xanxerê & $\begin{array}{l}\text { Relevo forte ondulado; } \\
\text { município limítrofes: Ipuaçu, } \\
\text { Bom Jesus, Xavantina, } \\
\text { Arvoredo, Faxinal dos } \\
\text { Guedes, Xaxim e Lajeado } \\
\text { Grande. }\end{array}$ & $\begin{array}{l}\text { Deficiências em relação à } \\
\text { acessibilidade; falta de um } \\
\text { plano turístico; } 28 \% \text { de } \\
\text { domicílios atendidos por rede } \\
\text { pública de água; } 29 \% \text { de } \\
\text { domicílios com acesso à rede } \\
\text { geral de esgoto ou fossa } \\
\text { séptica; } 43 \% \text { áreas de matas } \\
\text { e florestas naturais } \\
\text { preservadas nas } \\
\text { propriedades agropecuárias; }\end{array}$ & $\begin{array}{l}\text { Possui Plano Diretor; praça } \\
\text { central ampla e com boa } \\
\text { estrutura para eventos; } \\
\text { arborização de algumas ruas } \\
\text { com canteiros centrais; conta } \\
\text { com a estrutura de um } \\
\text { aeroporto; BR } 282 \text { corta a } \\
\text { cidade e possui infraestrutura } \\
\text { de acesso rápido; Museu com } \\
\text { rico acervo de peças } \\
\text { históricas; Possui feira de } \\
\text { exposição com presença de } \\
\text { grande público - FEMI; } \\
\text { ocorre atividades } \\
\text { relacionadas Agenda } 21 \text { e } \\
\text { licenciamento de impacto } \\
\text { local. }\end{array}$ \\
\hline Xaxim & $\begin{array}{l}\text { Relevo forte, ondulado; } \\
\text { município limítrofes: } \\
\text { Chapecó, Arvoredo, Xanxerê, } \\
\text { Lajeado Grande, Coronel } \\
\text { Freitas e Cordilheira Alta. }\end{array}$ & $\begin{array}{l}\text { Deficiências em relação à } \\
\text { acessibilidade; ausência de } \\
\text { rotas que explorem o turismo } \\
\text { do município; baixa } \\
\text { exploração dos atrativos } \\
\text { naturais e da fauna; pouca } \\
\text { exploração de passeios } \\
\text { alternativos no centro da } \\
\text { cidade; } 14 \% \text { de domicílios } \\
\text { com acesso à rede geral de } \\
\text { esgoto ou fossa séptica; } 66 \% \\
\text { de domicílios atendidos por } \\
\text { rede pública de água; falta de } \\
\text { articulação da Agenda } 21 \\
\text { local; }\end{array}$ & $\begin{array}{l}\text { Praça central ampla e com } \\
\text { boa estrutura para eventos; } \\
\text { possui Plano Diretor com lei } \\
\text { especifica de proteção do } \\
\text { patrimônio histórico; } \\
\text { investimentos e } \\
\text { conscientização do turismo; } \\
\text { diversidade de eventos; } \\
\text { preservação da cultura e da } \\
\text { religiosidade; ocorre } \\
\text { atividades relacionadas } \\
\text { licenciamento de impacto } \\
\text { local. }\end{array}$ \\
\hline
\end{tabular}

Nota: Dados da pesquisa coletados para compor a matriz de condicionantes deficiências e potencialidades.

As constatações demostradas na Matriz CDP revelam uma semelhança nas deficiências dos municípios, principalmente na questão de infraestrutura dos municípios. Todavia, devemos enfatizar os agentes descritos por Boullón (2002), uma vez que ocorre uma demanda do turismo, os municípios possuem oferta turística, seu processo de venda ainda é precário e todos os municípios contemplam o produto turístico e nesse caso enfatizamos as belezas cênicas, cachoeiras, reserva indígena, turismo rural, religioso e gastronômico. 
No entanto, não há uma infraestrutura que possa suportar a demanda turística e está necessita de investimento constante para o pleno funcionamento de todo o sistema turístico, pois todas as esferas dependem da infraestrutura para o seu continuo funcionamento. Os domicílios com acesso à rede geral de esgoto ou fossa séptica quando referidos em um pequeno percentual implicam diretamente nas questões ambientais, já os municípios que não contemplam bons indicadores de domicílios atendidos direta ou indiretamente por coleta de lixo e rede pública de água implicam diretamente na prestação do serviço turístico.

\section{Objetivo e metas estratégicas para promoção do turismo sustentável}

Por meio da Matriz Condicionantes, Deficiências e Potencialidades, foi proposto os objetivos estratégicos que visam solucionar os as fragilidades, destacando as potencialidades de forma intermunicipal. Estabelecemos as metas de forma a impulsionar o desenvolvimento do turismo integrado. As metas e os objetivos estão descritos no Quadro 2, juntamente com uma previsão de prazos sendo curto 1 ano, médio 2 anos e longo 5 anos.

Quadro 2: Objetivos e metas estratégicas.

\begin{tabular}{|c|c|c|}
\hline Objetivos estratégicos & Metas & Prazos \\
\hline $\begin{array}{l}\text { Desenvolver políticas públicas } \\
\text { voltadas para a promoção do turismo } \\
\text { sustentável }\end{array}$ & $\begin{array}{l}\text { Criação de Plano Diretores em todos os municípios da } \\
\text { análise, implantação das políticas públicas de forma } \\
\text { intermunicipais facilitando a comunicação e a relação } \\
\text { do turismo nos municípios. }\end{array}$ & $\begin{array}{l}\text { A curto prazo com alto } \\
\text { investimento inicial; }\end{array}$ \\
\hline $\begin{array}{l}\text { Implantar } 100 \% \text { de domicílios } \\
\text { atendidos direta ou indiretamente por } \\
\text { coleta de lixo, } 100 \% \text { de domicílios } \\
\text { atendidos por rede pública de água e } \\
\text { acesso à rede geral de esgoto ou fossa } \\
\text { séptica }\end{array}$ & $\begin{array}{l}\text { Propor ações de regularizações de obras que } \\
\text { contemplem } 100 \% \text { das edificações irregulares ou sem } \\
\text { cobertura de saneamento básico. }\end{array}$ & $\begin{array}{l}\text { Alto investimento em } \\
\text { infraestrutura urbana e } \\
\text { rural; investimento a longo } \\
\text { prazo; }\end{array}$ \\
\hline $\begin{array}{l}\text { Implantar a Agenda } 21 \text { local e } \\
\text { atividades relacionado licenciamento } \\
\text { de impacto local. }\end{array}$ & $\begin{array}{l}\text { Desenvolver estas atividades com a participação } \\
\text { intermunicipais }\end{array}$ & $\begin{array}{l}\text { Baixo investimento } \\
\text { financeiro, implantação a } \\
\text { curto prazo. }\end{array}$ \\
\hline $\begin{array}{l}\text { Promover e incentivar a criação de } \\
\text { áreas de matas e florestas naturais } \\
\text { preservadas nas propriedades } \\
\text { agropecuárias }\end{array}$ & $\begin{array}{l}5 \% \text { por ano, incentivar o uso dessas áreas para criação } \\
\text { de atividades turísticas; }\end{array}$ & $\begin{array}{l}\text { Baixo investimento } \\
\text { podendo ser executado a } \\
\text { longo prazo; }\end{array}$ \\
\hline $\begin{array}{l}\text { Incentivar a participação nos pleitos } \\
\text { eleitorais e a representatividade de } \\
\text { gêneros entre candidatos a } \\
\text { vereadores }\end{array}$ & $\begin{array}{l}10 \% \text { por ano, os incentivos deverão parti de cada } \\
\text { município até atingir } 100 \% \text {. }\end{array}$ & $\begin{array}{l}\text { Baixo investimento } \\
\text { podendo ser executado a } \\
\text { longo prazo; }\end{array}$ \\
\hline $\begin{array}{l}\text { Fomentar o turismo urbano e rural de } \\
\text { forma intermunicipal. }\end{array}$ & $\begin{array}{l}\text { Implantar rota turística passando pelos pontos } \\
\text { turísticos dentro dos municípios; promover ações de } \\
\text { sustentabilidade na agroindústria familiar. }\end{array}$ & $\begin{array}{l}\text { Investimento a longo } \\
\text { prazo, a rota turística } \\
\text { deverá integrar os } \\
\text { municípios onde poderão } \\
\text { manter ações paralelas de } \\
\text { investimento. } \\
\end{array}$ \\
\hline $\begin{array}{l}\text { Implantar e revitalizar o equipamento } \\
\text { urbano, tais como, lixeiros, banheiros, } \\
\text { bancos, pontos de iluminação e } \\
\text { floreiras; promover a acessibilidade } \\
\text { nas calçadas e estabelecimentos } \\
\text { comerciais. }\end{array}$ & $\begin{array}{l}\text { Desenvolver a revitalização de praças, trevos e ruas, } \\
\text { implantando mobiliário urbano atrativo, que componha } \\
\text { o espaço urbano e supra as necessidades de cada } \\
\text { espaço. }\end{array}$ & $\begin{array}{l}\text { Investimento a médio } \\
\text { prazo. }\end{array}$ \\
\hline $\begin{array}{l}\text { Incentivar a exploração de atividades } \\
\text { turísticas em pontos deslocados dos } \\
\text { centros municipais. }\end{array}$ & $\begin{array}{l}\text { Identificar os locais de possíveis potenciais para pratica } \\
\text { do turismo, incentivar o turismo rural juntamente com } \\
\text { a agricultura familiar. }\end{array}$ & $\begin{array}{l}\text { Baixo investimento } \\
\text { podendo ser a longo prazo. }\end{array}$ \\
\hline $\begin{array}{l}\text { Sensibilizar a comunidade por meio da } \\
\text { política da boa vizinhança. }\end{array}$ & $\begin{array}{l}\text { Promover cursos, palestras e treinamentos para gerar } \\
\text { habilidades de novos empreendedores; qualificar os }\end{array}$ & Investimento a curto prazo \\
\hline
\end{tabular}




\begin{tabular}{|l|l|l|}
\hline $\begin{array}{l}\text { Valorizar o patrimônio histórico, } \\
\text { arquitetônico e cultural do município }\end{array}$ & $\begin{array}{l}\text { existentes; promover a política da boa vizinhança. } \\
\text { Investir em restauração de locais, edificações e objetos } \\
\text { que resguardam a história da cidade e do início do } \\
\text { povoamento de cada município. }\end{array}$ & $\begin{array}{l}\text { Investimentos a longo } \\
\text { prazo, alto custo podendo } \\
\text { ser oferecido incentivos } \\
\text { tributários os proprietários } \\
\text { das edificações. }\end{array}$ \\
\hline $\begin{array}{l}\text { Conscientizar a exploração do turismo } \\
\text { sustentável }\end{array}$ & $\begin{array}{l}\text { Implantar rotas turísticas explorando o turismo } \\
\text { sustentável ambiental. Promover passeios alternativos } \\
\text { "bicicletas" que explorem os atrativos ambientais e a } \\
\text { beleza cênica das paisagens, os passeios podem } \\
\text { explorar a região central do município. Intensificar a } \\
\text { efetividade da estrutura de gestão ambiental e do } \\
\text { Conselho Municipal do Meio Ambiente }\end{array}$ & $\begin{array}{l}\text { Mobtruturar e manter sua } \\
\text { continuidade. } \\
\text { Investimentos a longo } \\
\text { prazo com médio custo. }\end{array}$ \\
\hline
\end{tabular}

Todos os objetivos estratégicos e metas citados no Quadro 2, devem ser planejados e executados seguindo os prazos de forma continua e paralelamente. Pois caso ocorra a interrupção ou atraso de qualquer uma das metas as outras prosseguem causando o menor impacto possível dentro de todo o contexto.

\section{Recomendações para o turismo sustentável nos municípios da AMAI}

Nessa etapa sugerimos dois viés de recomendações, o primeiro ligado a questão da infraestrutura do território municipal, direcionado exclusivamente em resolver os problemas encontrados na Matriz CDP, como a falta de calçadas e edificações que garantam a acessibilidade, o aumento dos indicadores de domicílios com acesso à rede geral de esgoto ou fossa séptica e atendidos por rede pública de água, bem como, a articulação da Agenda 21 local e as atividades relacionado licenciamento de impacto local.

No segundo viés relacionamentos as políticas públicas voltadas para a promoção do turismo sustentável intermunicipal. Essa etapa de investimento deverá estar diretamente relacionada com a demanda e oferta turística, ao processo de venda, e aos empreendimentos e atrativos turísticos, ou seja, no incentivo à exploração de atividades turísticas em pontos deslocados dos centros municipais, a sensibilização da comunidade por meio da política da boa vizinhança ao treinamento e capacitação do prestador de serviço turístico e a explorando o turismo sustentável intermunicipal.

Os dois vieses devem ser implantados juntos e ocorrer paralelamente. Ressaltamos que as criações de rotas turísticas facilitariam a promoção do turismo sustentável intermunicipal. Dessa forma, propomos cinco rotas intermunicipais que poderiam ser o ponto inicial para o desenvolvimento do turismo regional.

Quadro 3: Preposição de rotas intermunicipais.

\begin{tabular}{|l|l|}
\hline Rota das quedas & $\begin{array}{l}\text { Permite um passeio pelos municípios que tenham acesso ao rio Chapecó, com belas quedas e paisagens } \\
\text { deslumbrantes, sendo eles, Abelardo Luz, Entre Rios e Xanxerê. }\end{array}$ \\
\hline $\begin{array}{l}\text { Rota da } \\
\text { agricultura } \\
\text { familiar }\end{array}$ & $\begin{array}{l}\text { Permite ao pequeno agricultor expor o seu cotidiano, demonstrando as principais produções geradas pela } \\
\text { sua propriedade, bem como, a venda de produtos agrícolas. Essa rota abrange todos os municípios da } \\
\text { associação da AMAl. }\end{array}$ \\
\hline $\begin{array}{l}\text { Rota } \\
\text { gastronômica }\end{array}$ & $\begin{array}{l}\text { Esta rota destacaria as pequenas propriedades seja ela rural ou urbana, com interesse na exploração do } \\
\text { turismo gastronômico, desde um ponto comercial, restaurante ou as associações de bairros e comunidades } \\
\text { que se propunham desenvolver atividades relacionadas à cultura e a gastronomia como o Filó e as festas } \\
\text { tradicionais. }\end{array}$ \\
\hline Rota religiosa & $\begin{array}{l}\text { Permite aos turistas um passeio pelos municípios da microrregião da AMAl, visitando as igrejas locais, bem } \\
\text { como, grutas e pontos específicos de turismo religioso. }\end{array}$ \\
\hline Rota ambiental & $\begin{array}{l}\text { Esta rota estaria voltada aos esportes radicais, seria uma trilha que interligasse todos os municípios e várias } \\
\text { propriedades. Em trechos dentro da mata e por estradas rurais com contato direto a natureza, podendo ser } \\
\text { realizada de bicicleta ou caminhada. }\end{array}$ \\
\hline
\end{tabular}


As rotas promovem a interação do turista com o morador local, permitindo a conscientização sustentável do ambiente. Elas surgem como uma forma de incentivo na promoção do turismo sustentável. E ao mesmo tempo em que se implanta cada rota outras rotas menores podem ser criadas. No entanto, percebemos que os investimentos para a promoção do turismo sustentável intermunicipal são altos e demandam de uma organização efetiva e continua.

O que propomos são formas de facilitar e nortear a exploração do turismo no Oeste Catarinense. Percebemos que esta região possui grande potencial a ser explorado de forma sustentável, englobando os aspectos político institucional, sociocultural, ambiental e econômico, tornado uma nova proposta de lazer e renda aos envolvidos nesse processo.

\section{CONCLUSÕES}

O objetivo desta pesquisa delimitou-se a desenvolver um estudo estratégico que possa servir de suporte para o desenvolvimento sustentável do turismo nos municípios que compõem a região da Associação dos Municípios do Alto Irani - AMAI. Nesse sentido, respondemos na integra o objetivo, pois por meio da Matriz Condicionantes, Deficiências e Potencialidades (CDP) conseguimos identificar as fragilidades e as potencialidades intermunicipais de forma a criar meios que possibilitem o cumprimento dos objetivos estratégicos e das metas pré-estabelecidas promovendo o turismo sustentável regional.

Respondemos à pergunta da pesquisa por meio dos resultados gerados pela Matriz Condicionantes, Deficiências e Potencialidades (CDP) e pelos objetivos estratégicos desenvolvidos, propondo metas a curto, médio e longo prazo. Constatamos a necessidade de investimentos em dois vieses sendo um em infraestrutura urbana e rural e o outro em políticas públicas voltadas para a promoção do turismo sustentável intermunicipal. Como contribuição o estudo demostra os pontos mais frágeis que devem ser corrigidos e os pontos fortes que podem ser explorados. Destacamos, que as correções dos pontos frágeis além de melhorar o turismo irão elevar os indicadores de desenvolvimento municipal sustentável.

O estudo está limitado em uma análise documental e da Matriz Condicionantes, Deficiências e Potencialidades (CDP), bem como restrito apenas nos municípios que compõem a região da AMAl. Como recomendações para futuros estudos destacamos a ampliação do estudo abrangendo mais municípios aos redores da região da AMAI, bem como ampliação das rotas turísticas explorando as potencialidades citadas na matriz. Para obtenção do sucesso do estudo os objetivos estratégicos devem ser implantados e estruturados mantendo sua continuidade e verificando constantemente se os pontos fracos demostrados na pesquisa foram sanados com resultado esperado.

Buscamos demostrar nesse estudo uma análise da problemática do desenvolvimento do turismo intermunicipal na região da AMAI, onde a pergunta da pesquisa foi transformada em objetivo estratégico de forma a melhorar o turismo e seus indicadores aumentando a competitividade do turismo sustentável no Oeste Catarinense. 


\section{REFERÊNCIAS}

AMAI. Associação dos Municípios do Alto Irani. Histórico da região da AMA. AMAI, 2017.

BENI, C. M.. Política e Estratégia do Desenvolvimento Regional: Planejamento Integrado e Sustentável do Turismo. Turismo em Análise, v.10, n.1, p.7-17, 1999.

BEZERRA, D. F.. Planejamento e gestão do turismo. São Paulo: Roca, 2003.

BOULLÓN, R. C.. Planejamento do espaço turístico. Bauru: Edusc, 2002.

BRASIL. Ministério do Turismo. Programa de Regionalização do Turismo: Roteiros do Brasil. Brasília: Ministério do Turismo, 2007.

FECAM. Federação Catarinense de Municípios. Sistema de Indicadores de Desenvolvimento Municipal Sustentável. Florianópolis: FECAM, 2016.

FIESC. Federação das Indústrias do Estado de Santa Catarina. Iniciativa de peso para alavancar o turismo em Santa Catarina. Turismo \& Negócios. Florianópolis: FIESC, 2015.

HELDER, R. R.. Como fazer análise documental. Porto Alegre: Universidade de Algarve, 2006.

IBGE. Instituto Brasileiro de Geografia e Estatística. Censo Demográfico de 2014. Rio de Janeiro: IBGE, 2014.
IBGE. Instituto Brasileiro de Geografia e Estatística. Estimativa populacional de 2016. Rio de Janeiro: IBGE, 2016.

ICTN. Índice de Competitividade do Turismo Nacional. Relatório Brasil Brasília: Ministério do Turismo. ICTN, 2015.

MOLINA, E. S.. Turismo e ecologia. Bauru: EDUSC, 2001.

RUSCHMANN, D. V.. Turismo e desenvolvimento sustentável: a proteção do meio ambiente. Campinas: Papirus, 1997.

SACHS, I.. Caminhos para o desenvolvimento sustentável. Rio de Janeiro: Garamond, 2008.

SANTA CATARINA. Programa de capacitação técnica para o planejamento urbano. Florianópolis: SDM, 1999.

SANTA CATARINA. Secretaria de Estado de Turismo, Cultura e Esporte. Estudo da demanda turística do estado de Santa Catarina. Florianópolis: SANTUR, 2016.

SIEBERT, C.; SOUZA, A.. Panorama do planejamento regional em Santa Catarina: da centralização à construção da solidariedade regional. Blumenau: FURB, 2001.

WAHAB. S.. Introdução à administração do turismo: alguns aspectos estruturais e operacionais do turismo internacional teoria e prática. São Paulo: Pioneira, 1991.

A CBPC - Companhia Brasileira de Produção Científica (CNPJ: 11.221.422/0001-03) detém os direitos materiais desta publicação. Os direitos referem-se à publicação do trabalho em qualquer parte do mundo, incluindo os direitos às renovações, expansões e disseminações da contribuição, bem como outros direitos subsidiários. Todos os trabalhos publicados eletronicamente poderão posteriormente ser publicados em coletâneas impressas sob coordenação da Sustenere Publishing, da Companhia Brasileira de Produção Científica e seus parceiros autorizados. Os (as) autores (as) preservam os direitos autorais, mas não têm permissão para a publicação da contribuição em outro meio, impresso ou digital, em português ou em tradução. 